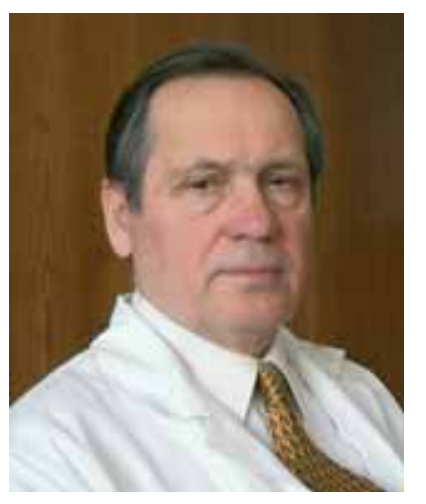

А.Г.Чучалин

Отек легких:

физиология легочного кровообращения и патофизиология отека легких

НИИ пульмонологии Росздрава

\title{
A.G.Chuchalin \\ Pulmonary oedema: physiology of lung circulation, pathophysiology of pulmonary oedema
}

Отек легких является жизнеугрожающим осложнением, которое может развиться при большой и разнообразной по своей природе группе заболеваний. В современной медицинской практике разделяют несколько клинических форм отека легких: кардиогенный и некардиогенный отек легких, острое повреждение легких, острый респираторный дистресссиндром, неврогенный отек легких. В последние годы, преимущественно в англоязычной литературе, накопилась большая информация по этому разделу патологии внутренних органов. Необходимо подчеркнуть, что опубликованы согласительные документы Американского торакального и Европейского респираторного обществ по определению острого респираторного дистресс-синдрома, диагностическому алгоритму кардиогенного и некардиогенного отека легких, рекомендованы новые диагностические и лечебные программы по ведению больных с отеком легких. Назрела необходимость представить современную трактовку данной проблемы и в русскоязычной медицинской литературе. В представленной серии статей последовательно освещаются вопросы физиологии легочного кровообращения и патофизиологии отека легких. Если 1-я статья является аналитическим обзором по проблеме патофизиологии отека легких, то последующие 2 статьи - клиническими лекциями. 2-я статья посвящена классификации и клиническим проявлениям различных форм отека легких и, наконец, 3-я - современным лечебным программам. Легочное кровообращение - гемодинамическая система, которая объединяет работу правого и левого желудочка; в кровообращении человека эта его часть выделена как малый круг кровообращения. Основная гемодинамическая функция малого круга кровообращения состоит в доставке полного ударного объема крови правого желудочка в русло легочных сосудов, ее транспорте по ним, и завершает малый круг левое предсердие, которое наполняется кровью, доставленной легочными венами. Транспорту крови способствуют низкое давление в системе малого круга кровообращения и относительно низкие показате- ли сопротивления сосудов току крови. За предельно короткое время, которое не превышает 1 с, происходит диффузия кислорода и углекислого газа, т. е. реализуется одна из основных функций легких - газообмен. Другой важной функцией легочного кровообращения являются высвобождение и метаболизм большой группы медиаторов, принимающих участие в самых разнообразных процессах человеческого организма. Морфологическая организация легочной ткани и легочное кровообращение играют важную роль в регуляции водного и электролитного баланса. Эти три функции легочного кровообращения: газообмен, регуляция обмена электролитов и воды, а также участие в метаболизме биологически активных субстанций - тесно взаимосвязаны и дополняют друг друга. Следует подчеркнуть, что толщина альвеолокапиллярной мембраны не превышает 1-2 ммк, ее площадь около 70 м² и в течение 0,75 с происходит диффузия кислорода и углекислоты. Высокая биологическая эффективность достигается за счет развитой системы легочного кровообращения и уникальной морфологической организации легких (Albertine, et al.) [1].

Легочное кровообращение начинается в правом желудочке, и кровь изначально поступает в основной ствол легочной артерии, длина которой не превышает 5 см, а ширина - около 3 см. Размеры основного ствола легочной артерии необходимо учитывать особенно в тех случаях, когда речь идет о развитии первичной и вторичной легочной гипертензии, в более редких случаях встречается аневризматическое расширение a. pulmonalis. Основная часть ствола легочной артерии проходит через аортальное окно и вскоре делиться на 2 ветви: правую и левую. Правая ветвь легочной артерии, в свою очередь, делится на верхнюю и нижнюю ветви. Верхняя ветвь правой легочной артерии подходит к верхней доле правого легкого, в то время как нижняя, которая больше размером, чем верхняя, делиться на 2 ветви: одна из которых подходит к средней доле легкого, а другая - к нижней. Левая ветвь, которая отходит от основного ствола легочной артерии, располагается над левым главным 
бронхом и делится на верхнюю и нижнюю ветви. Легочные артерии и бронхи окружены одной и той же соединительной тканью и идут параллельно друг другу вплоть до альвеол и капилляров. Легочные артерии представлены 2 формами. В отличие от 1-й формы, которая была описана выше, 2-я лежит в паренхиматозной ткани легких и анатомически не связана с бронхом. На долю 2-го типа артерий приходится около $25 \%$ в области корней легких и около $40 \%$ - на периферии. Этот тип легочных артерий играет важную роль в развитии коллатерального кровообращения.

Особенность гемодинамики малого круга кровообращения связана с низкой резистентностью легочных сосудов; она в легочных сосудах составляет 10-ю часть от общей периферической резистентности сосудов большого круга кровообращения. Как артерии, так и вены малого круга кровообращения имеют мышечный слой, который менее выражен, если сравнить с сосудами этого же диаметра других органов человеческого организма. Однако мышечный слой легочных артерий развит более выражено, чем это можно наблюдать в структуре легочных вен. Большие легочные артерии, диаметр которых превышает 1-2 мм, относятся к эластическому типу. Эластические волокна покрывают мышечный слой. Мышечная часть начинает доминировать в структуре артерий с уменьшением их диаметра; при диаметре сосудов менее 100 ммк мышечные волокна распределены неравномерно. Их расположение можно сравнить с сэндвичем: тонкий слой мышечных волокон лежит между хорошо очерченным слоем внутренних и внешних слоев эластических волокон. Мышечные волокна исчезают, и стенка сосуда состоит из монослоя эндотелиальных клеток и эластических волокон (elastic lamina). Сосуды диаметром < 30 ммк не имеют мышечных волокон. Однако при хронической гипоксии происходит пролиферация гладких мышц, и они появляются и в структуре мелких сосудов малого круга кровообращения (Fishman) [2].

Легочные вены значительно тоньше артерий и подобно им присутствуют в 2 формах. 1-й тип легочный вен определен как "обычный", в противоположность ему выделяются вены, свободно расположенные внутри легочной ткани. Маленькие по размерам вены объединяются в более крупные, и, в конце концов, вены от долей легких доставляют кровь в левые отделы сердца. Верхняя и средняя легочные вены правого легкого объединяются в верхнюю легочную вену. Таким образом, 4 вены доставляют кровь в левое предсердие. Сосуды легких характеризует высокая степень податливости к изменяющимся условиям легочного кровообращения, что отличает их от системного кровообращения. Эту функциональную особенность объясняют относительно небольшим числом мышечных волокон, входящих в структуру сосудов малого круга кровообращения. Легочные сосуды могут играть роль резервуара крови, как, например, это происходит при физической нагрузке или же у больных с проявлениями застойной сердечной недоста- точности. Мышечные, эластические и коллагеновые волокна могут варьировать просвет сосудов и таким образом влиять на количество крови, проходящей через их просвет.

Отдельная система легочного кровообращения связана с бронхиальными артериями. Этот тип артерий обеспечивает поступление крови к дыхательным путям от карины до терминальных бронхиол. На долю бронхиальных артерий от ударного объема крови приходится менее $3 \%$.

Таким образом, легочное кровообращение представлено выходным трактом правого желудочка, основным стволом легочной артерии, главными ветвями легочной артерии и их лобными ветвями, внутрилегочными артериями, большими артериями эластического типа, маленькими артериями мышечного типа, артериолами, капиллярами, венулами и большими легочными венами, впадающими в левое предсердие. В функциональном отношении они подразделены на 2 большие группы: экстраальвеолярные и альвеолярные сосуды. Это подразделение носит относительный характер, но оно имеет значение в патогенетических механизмах развития отека легких.

Интерфейс крови и газов осуществляется в густой сети легочных капилляров, которые лавируют в паренхиматозной ткани альвеолярных перегородок, представленных тонкими нитями коллагена и эластическими волокнами. Капиллярное ложе описывается как гексагональная сеть цилиндров, в которой длина и ширина цилиндра не отличаются по своим размерам. Другой формой организации капиллярного ложа является форма полоски; при этом варианте оба конца капилляра связаны с альвеолярной перегородкой (рис. 1).

Перфузия капилляров кровью начинается, как только давление внутри капилляра превысит альвеолярное давление. Дальнейшее повышение давления внутри капилляров и повышение перфузии уже зависит от растяжения альвеолярной стенки, положительного давления в дыхательных путях и гравитационных характеристик крови.

Легочные капилляры проходят свой путь через интерстициальную ткань межальвеолярных перегородок, вступая в контакт вначале с одной альвеолой, в последующем - с другой; таким образом, каждый капилляр контактирует с несколькими альвеолами.

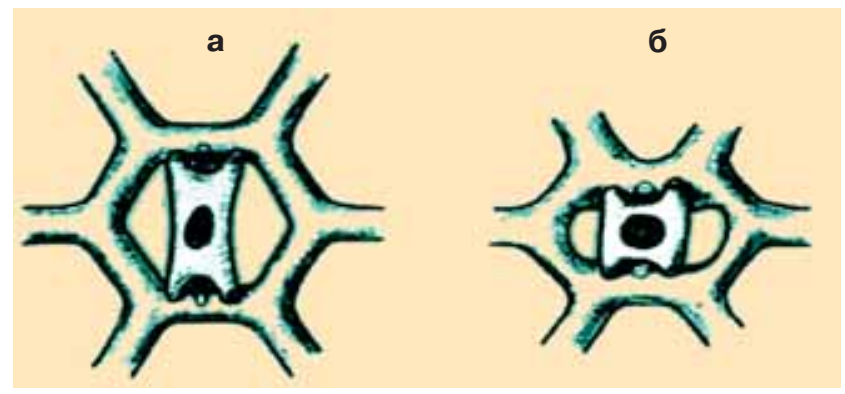

Рис. 1. Схематичное изображение гексагонального расположения альвеолярных капилляров в период релаксации (а) и констрикции (б) (Fishman, 1990) [2] 
Капиллярный эндотелий представлен монослоем эндотелиальных клеток, так что просвет капилляра напоминает трубочку. Эндотелиальные клетки капилляров и альвеол (пневмоциты 1-го и 2-го типов) разделяет базальная мембрана. Выделены 2 формы морфологической организации эндотелиальных клеток капилляров и альвеол и базальной мембраны. 1-й тип характеризуется утонченными структурами базальной мембраны, и эта часть является идеальной для диффузии кислорода и диоксида азота. 2-я форма, для которой характерно утолщение базальной мембраны, включает такие морфологические элементы соединительной ткани, как коллаген 1-го и 4-го типов, обеспечивая структурную организацию базальной мембраны. В утолщенной части базальной мембраны преимущественно осуществляются водный и электролитный обмены, т. е. эта часть альвеол защищена от проникновения воды в альвеолярное пространство. Таким образом, барьеры альвеолярного пространства и сосудистого русла состоят из эпителиальных клеток альвеол, базальной мембраны и эндотелиальных клеток капилляров, интерстициальной ткани, из которой построены альвеолярные перегородки (рис. 2).

Давление и поток крови по сосудам малого круга кровообращения носит пульсативный характер. Давление в системе артериальных сосудов малого круга кровообращения носит убывающий характер, однако его характер сохраняется и в венозной части кровообращения. Систолическое давление в легочной артерии в норме составляет 25 мм рт. ст., диастолическое - 9 мм рт. ст. Эти цифры свидетельствуют о том, что давление в системе легочной артерии существенно ниже, чем в большом круге кровообращения.

Трансмиссионная электронограмма человеческого легкого (рис. 2) демонстрирует механизм диффузии кислорода и диоксида углерода. Тонкая часть альвеолярной стенки состоит из альвеоцитов 1-го ти-

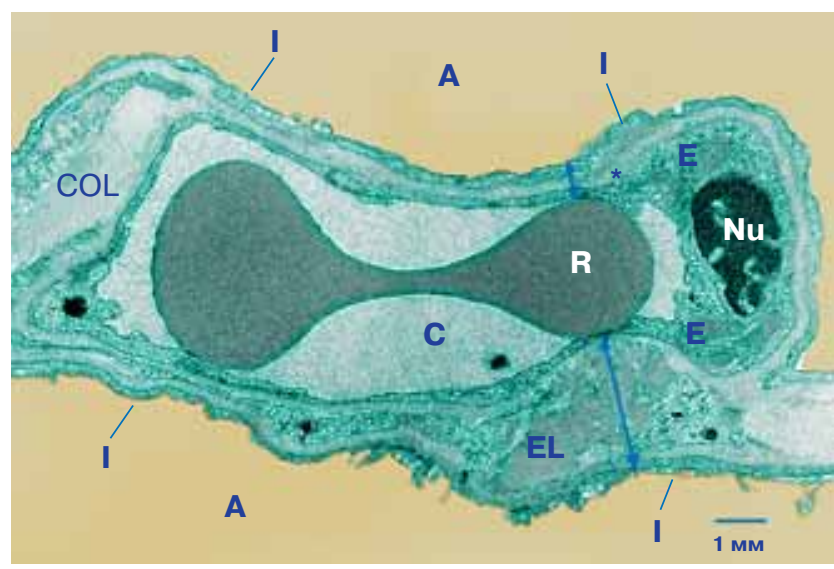

Рис. 2. Трансмиссионная электронограмма человеческого легкого: механизм диффузии кислорода и диоксида углерода (цитируется по Mason et al. [3])

Короткими стрелками показана тонкая часть альвеолярной стенки, состоящей из альвеоцитов 1-го типа (I), интерстиция (*), эндотелиальных клеток капилляров (E), плазмы внутри капилляров (C), цитоплазмы эритроцитов (R); длинными стрелками отмечена утолщенная часть базальной мембраны; $\mathrm{El}$ - эластин; COL коллаген; А - альвеолы; $\mathrm{Nu}$ - ядро эндотелиальных клеток. па, интерстиция, эндотелиальных клеток капилляров, плазмы внутри капилляров, цитоплазмы эритроцитов. Утолщенная часть базальной мембраны аккумулирует эластин, коллаген и матрикс, который отсепарировал альвеолярный эпителий от альвеолярных капилляров. По мере того как эритроцит проходит через альвеолярный капилляр, диффузия кислорода и диоксида углерода осуществляется как в тонкой части альвеолокапиллярной мембраны, так и в утолщенной (цитируется по Mason et al. [3]).

Следует подчеркнуть, что давление в артериальном русле малого круга кровообращения разное и зависит от места, где оно было измерено. Так, оно возрастает к диафрагме, и более низкое артериальное давление можно измерить в верхних отделах легких. Точное измерение давления в системе легочной артерии производится методом постановки плавающего катетера Swan-Ganz, в частности, можно измерить давление заклинивания (pulmonary artery wedge pressure). В норме показатель давления заклинивания не превышает 10 мм рт. ст. Данный параметр гемодинамики малого круга кровообращения используется при проведении дифференциального диагноза между кардиогенным и некардиогенным отеком легких. Так, показатели давления заклинивания, которые превышают 10 мм рт. ст., свидетельствуют в пользу кардиогенной природы отека легких. Экстраполируется положение, что давление заклинивания отражает уровень давления в легочных венах и, значит, в левом предсердии. Установлена закономерность взаимоотношений между давлениями в альвеолах, легочной артерии и легочных венах. В верхних отделах дыхательных путей давление в альвеолах превышает давление в легочной артерии, а последнее - давление в легочных венах. При таких гемодинамических условиях перфузия сосудов, в данном случае апикальных отделов легких, является минимальной. В базальных отделах легких устанавливается другое взаимоотношение: давление в легочной артерии превышает давление в легочных венах, последнее - превышает давление в альвеолах. В этих отделах легких наблюдается наибольшая перфузия. Промежуточное положение занимает средняя зона легких.

Резистентность легочных сосудов (PVR) рассчитывается по следующей формуле:

$$
P V R=\frac{P P A-P L A}{Q T},
$$

где QT - кровототок к легочной артерии; PLA давление в левом предсердии во время систолы предсердия (обычно устанавливается по показателям давления заклинивания); РРА - давление в легочной артерии.

PVR рассчитывается в единицах, которые записываются следующим образом: мм рт. ст. / $\pi^{-1} /$ мин $^{-1}$. B норме PVR составляет 0,1 мм рт. ст. / $\pi^{-1} /$ мин $^{-1}$ или 100 дин $/ \mathrm{c}^{-1} / \mathrm{cm}^{-1}$. Из представленной формулы видно, что резистентность не будет зависеть от давления в легочной артерии, если одновременно 
повысится давление в левом предсердии. Профиль резистентности сосудов легких был изучен с помощью микропункций сосудов. В нижних отделах дыхательных путей резистентность легочных сосудов не зависит от давления в альвеолах; основная часть резистентности определяется сопротивлением в микрососудах, т. е. в легочных капиллярах. Результаты этих исследований указали, что небольшого диаметра артериальные сосуды и капилляры приводят к гемодинамическому эффекту, который заключается в снижении давления при прохождении крови через капиллярное ложе. В этом состоит отличительная особенность кровообращения легких от системного. Таким образом, методом микропункций сосудов было показано, что давление падает в прекапиллярных артериях и в альвеолярных капиллярах. На давление в сосудах оказывают влияние многие факторы: внутриплевральное, альвеолярное давление и т. д.; в зависимости от функциональной зоны легких (например, апикальная часть легких, базальная часть и т. д.) каждый из факторов по-разному влияет на формирование давления внутри сосудов. Экстраальвеолярные сосуды определены как внутрилегочные, на формирование давления оказывает влияние внутриплевральное давление и не оказывает гемодинамически значимого влияния альвеолярное давление. Внутриплевральное давление рассчитано как давление, которое тождественно давлению интерстициальной жидкости. Эти параметры имеют патогенетическое значение в формировании интерстициальной фазы отека легких. На давление в экстраальвеолярных сосудах оказывают влияние также гиперинфляция легочной ткани и изменения эластической тяги легких. Альвеолярные сосуды - преимущественно капилляры; анатомически они расположены в межальвеолярных перегородках. Они окружены альвеолами, и давление в них оказывает гемодинамически значимое влияние на перфузию капилляров. Повышенное давление в альвеолах приводит к эффекту компрессии капилляров. Угловые сосуды (corner vessels) входят в состав утолщенной части межальвеолярной перегородки и расположены между 3 альвеолами. Этот тип капилляров не подвержен влиянию давления в альвеолах, таким образом, сохраняется перфузия капиллярной сети, даже если давление в альвеолярном пространстве повышено.

Необходимо подчеркнуть, что при развитии эмфиземы, которая сопровождается увеличением мертвого пространства, происходит значительное увеличение резистентности в альвеолярных сосудах, в то время как в экстраальвеолярных сосудах резистентность снижается. На сопротивление в легочных сосудах оказывает влияние вязкость крови, протекающей через малый круг кровообращения. Вязкость оказывает влияние также на способность эритроцитов деформироваться (деформибельность), что имеет большое значение в механизмах диффузии газов. Давление в легочной артерии повышается с увеличением гематокрита, по которому оценивается вяз- кость крови. Таким образом, вязкость крови является фактором, оказывающим влияние на давление в легочной артерии, формирование сопротивления в легочных сосудах, диффузионную способность легких.

Комплайнс сосудов малого круга кровообращения характеризуется как очень высокий. Около 10 \% циркулирующей крови в организме человека приходится на малый круг кровообращения. Кровь распределяется между артериями, капиллярами и венами. В капиллярах находится около 75 мл крови, что составляет от 10 до $20 \%$ той крови, которая в данный момент находится в малом круге кровообращения. Однако количество крови в капиллярах может повышаться до 200 мл и более. Зависимость между давлением и объемом крови в сосудах легких носит линейный характер, но этот характер зависимости меняется при повышении давления, и он уже становиться нелинейным. Сосуды мелкого диаметра играют ведущую роль в формировании комплайнса легочного кровообращения. Этот физиологический процесс контролируется симпатической активностью. При возрастании симпатической активности происходит снижение комплайнса. Наполнение сосудов кровью и ее циркуляция зависит от анатомического места в легких. Так, в верхних апикальных частях легких при повышении трансмурального давления происходит циркуляция крови, в то время как в базальных отделах легких преобладает наполнение сосудов кровью. West et al. описали вертикальный принцип легочного кровообращения: в апикальной части легких внутрисосудистое давление наиболее низкое, и оно возрастает в базальной части легких. Эти особенности гемодинамики легких имеют клиническое значение при развитии отека легких. Влажные дистанционные хрипы изначально локализуются в верхних отделах легких, а в последующем, когда клиническая картина отека легких носит развернутый характер, они распространяются на средние и нижние участки легких.

Тонус легочных сосудов очень чувствителен к напряжению кислорода. При альвеолярной гипоксии, когда напряжение кислорода в альвеолах ниже 70 мм рт. ст., вызывается типичная вазоконстрикторная реакция. Увеличение резистентности в сосудистой системе легких связано с констрикцией прекапиллярных сосудов. В этом состоит отличие сосудов малого круга кровообращения от сосудов большого круга, которые на гипоксию отвечают эффектом дилатации. Констрикторная реакция прекапиллярных сосудов легких является фенотипическим свойством гладких мышц этих сосудов. Попытка дать объяснение этой реакции с позиции роли пептидэргических нервов или же аксонового рефлекса не дала результата. Активно изучается роль большой группы биологически активных субстанций: катехоламинов, гистамина, серотонина, ангиотензина II, тромбоксана, лейкотриена C4, фактора активации тромбоцитов, а также исследуется роль оксида азота. В клинической практике было показано, что вазоконстикторная реакция снижается при назначении нитроглицерина и ингаляций оксида 
азота. Однако найти медиатор или выделить ведущий механизм стимуляции нервной активности не удалось. В настоящее время основным объяснением является гипотеза прямого влияния гипоксии на функцию мышечных волокон посредством ингибирования калиевых и кальциевых каналов. Кальциевые каналы открываются в условиях гипоксии, и кальций накапливается в мышечных волокнах артерий малого круга кровообращения. Кальциевая теория основана на повышенной его концентрации в гладких мышцах сосудов. Кальций приводит к фосфорилизации миозина и вазоспастическим реакциям.

Отек легких определяется как состояние, для которого характерной особенностью является процесс аккумуляции воды в экстравазальном пространстве легких. Когда вода заполняет альвеолы (альвеолярная фаза отека легких), отек легких сопровождается выраженной артериальной гипоксемией. Гравиметрическим методом было проведено исследование содержания воды в легочной ткани. Она превышает $80 \%$ от всего веса легких. При отеке легких вода изначально накапливается в интерстициальной легочной ткани, и в случаях дальнейшего нарушения водно-электролитного обмена в легких, вода пропитывается на поверхность альвеол. Формализация водного обмена в легочной ткани достигается с помощью описаного Старлингом закона, известного как гипотеза Старлинга. С 20-х гг. прошлого столетия было много разнообразных модификаций формулы Старлинга. Однако основной принцип взаимоотношения гидростатического и онкотического давления остался незыблемым. Этот закон формализует одну из основных функций эндотелиальных клеток капилляров легких, которые играют роль барьера, предотвращая пропитывание воды, протеинов и электролитов на поверхность альвеол.

Современная запись закона Старлинга такова:

$$
E V L W=\left(L_{p} \times S\right)\left[\left(P_{c}-P_{i}\right)-\sigma\left(\Pi_{c}-\Pi_{i}\right)\right]-\text { lymph flow, }
$$

где EVLW - количество воды, которая находится за пределами сосуда, мл; $\mathrm{L}_{\mathrm{p}}$ - гидравлическое давление воды, см × мин $^{-1}$ мм рт. ст. ${ }^{-1} ; \mathrm{P}_{\mathrm{c}}, \mathrm{P}_{\mathrm{i}}$ - отражают гидростатическое давление внутри сосуда и в интерстициальной ткани, мм рт. ст.; П,$~ \Pi_{i}-$ показатели онкотического давления (мм рт. ст.); $\sigma-$ коэффициент для прохождения белка через базальную мембрану.

На рис. 3 схематично представлено взаимоотношение между интерстицием, альвеолами и сосудами.

Согласно модифицированной формуле Старлинга накопление жидкости в межсосудистом пространстве произойдет в случае повышения гидростатического давления внутри капилляров. Однако этот механизм будет реализован при условии, если не произойдет компенсированного повышения гидростатического давления в интерстициальной ткани. В случаях нарушения целостности эндотелиального покрова капилляров, как это происходит при развитии респираторного дистресс-синдрома, жидкость, электролиты и белки будут поступать в альвеолярное пространство.
Эти патологические изменения приводят к грубым нарушениям газообменной функции легких, что и является причиной развития острой гипоксемии.

В последнее время большое внимание уделяется исследованию механизмов пропитывания белка в альвеолярное пространство. Этот процесс был формализован Kedem and Katchalsky:

$$
J_{S}=J_{V}(1-\sigma) C_{S}+P S\left(C_{c}-C_{i}\right),
$$

где $\mathrm{J}_{\mathrm{s}}$ - растворимое вещество, мг / минута; $\mathrm{J}_{\mathrm{v}}$ - объем жидкости, который рассчитывается по формуле Старлинга; P - проницаемость, см / с; $\mathrm{C}_{\mathrm{s}}$ - средняя молярность растворимого вещества, находящегося на мембране; $\left(\mathrm{C}_{\mathrm{c}}-\mathrm{C}_{\mathrm{i}}\right)-$ градиент концентрации растворимого вещества в капилляре и интерстициальной ткани.

Фильтрация завершается в альвеолах, т. к. гидростатическое давление внутри капилляров снижается по мере прохождения крови; в венулярной части осуществляется процесс реабсорбции. Однако речь идет в данном случае об идеальной гемодинамической модели. Дилатация артерий малого диаметра приводит к увеличению гидростатического давления $\left(\mathrm{P}_{\mathrm{c}}\right)$, что означает увеличение объема фильтрации легочных капилляров. Вазоспастические реакции приведут к снижению $\mathrm{P}_{\mathrm{c}}$, что будет сопровождаться снижением фильтрации в капиллярах альвеол и повышению реабсорбции в венулах. Согласно закону

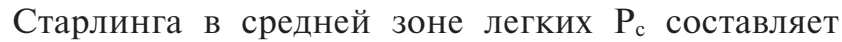
10 мм рт. ст., $\mathrm{P}_{\mathrm{i}}-3$ мм рт. ст., $\Pi_{\mathrm{c}}-25$ мм рт. ст., $\Pi_{\mathrm{i}}-$ 19 мм рт. ст. П м можно определить осмометром, т. к. показано, что онкотическое давление внутри сосудов можно сопоставить с концентрацией белка в плазме. Согласно представленным данным утверждается, что фильтрация происходит при разнице гидростатического давления в 7 мм рт. ст., что означает превалирование фильтрации над адсорбцией. Учитывая большую разницу в соотношении гидростатического давления в различных зонах легких, взаимоотношение фильтрации и реабсорбции также будет разным.

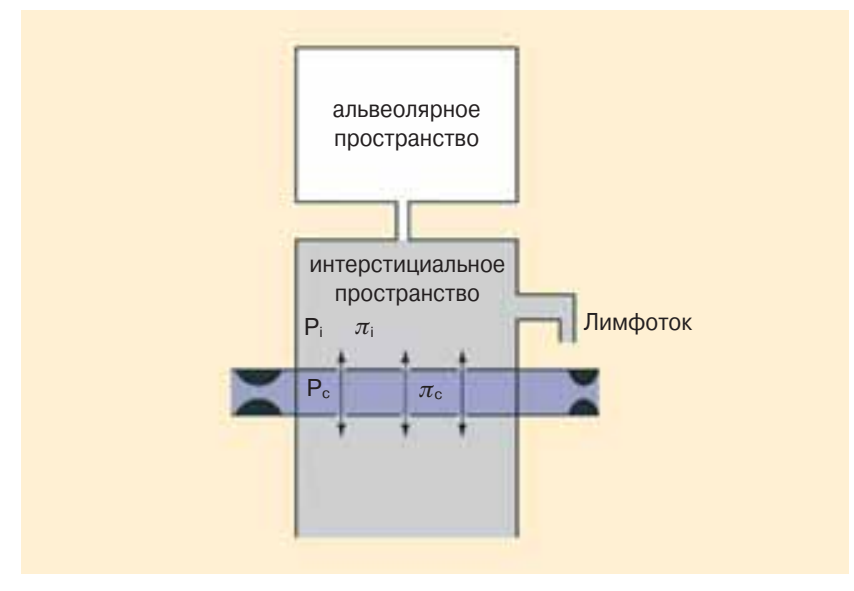

Рис. 3. Схема взаимоотношений между интерстицием, альвеолами и сосудами

$\mathrm{P}_{\mathrm{i}}$ - гидростатическое давление интерстиция; $\mathrm{P}_{\mathrm{c}}$ - гидростатическое давление сосудов; $\pi_{\mathrm{i}}-$ онкотическое давление в интерстиции; $\pi_{\mathrm{c}}-$ онкотическое давление в сосудах. 
Осмотическое давление плазмы составляет около 6000 мм рт. ст., в то время как онкотическое давление колеблется в пределах 25 мм рт. ст. Онкотическое давление играет важную роль в прохождении белков через полупроницаемую базальную мембрану альвеол. При увеличении проницаемости мембраны альбумин в большом количестве поступит в альвеолярное пространство.

Движение электролитов через поры эндотелиальных клеток определяется зависимостью, формализованной Kedem and Katchalsky. Градиент концентрации электролитов быстро выравнивается по обе стороны базальной мембраны.

Диффузия является ключевым фактором в обмене газов и электролитов. Диффузионная способность базальной мембраны записывается следующим образом:

$$
\mathrm{J}=\mathrm{DA}|\mathrm{dc} / \mathrm{dx}| \text {, }
$$

где $\mathbf{J}$ - количество субстанции, которое за единицу времени проходит через мембрану; D - диффузионная способность мембраны особенно относительно молекул; А - диффузионный путь мембраны; dc / dx - градиент концентрации электролитов, проходящих через базальную мембрану.

Диффузионная способность мембран колеблется в зависимости от природы молекул. Липидонерастворимые молекулы (какими являются белки) задерживаются порами эндотелиальных клеток. Молекулярный вес выше 60 кДа препятствует прохождению молекул через поры. Большую роль играет электрический заряд. Эндотелиальные клетки легочных капилляров заряжены отрицательно, что оказывает влияние на диффузию соединений с противоположным зарядом. Необходимо подчеркнуть, что эндотелиальные клетки представляют обширную поверхность и являются местом, где осуществляются фильтрация и диффузия. Описано несколько путей, через которые происходит транспорт воды и электролитов: везикулы, межэндотелиальные соединения, трансэндотелиальные каналы. Соединения с низким молекулярным весом липидрастворимые (липофильные), и диффузия их водой осуществляется непосредственно через эндотелиальные клетки (трансцеллюлярный путь диффузии). Липофильные молекулы, такие как кислород и диоксид углерода, диффундируют непосредственно через всю поверхность эндотелиальных клеток капилляров. Диффузия воды также осуществляется через эндотелий микрососудов; местом их диффузии являются водные каналы этих клеток. Макромолекулы и низкомолекулярные водорастворимые соединения транспортируются через интерэндотелиальные соединения, а также возможна их диффузия трансцеллюлярным путем. Важной характеристикой эндотелиального барьера является экстрацеллюлярный матрикс. Он состоит из большого числа молекул, из которых наиболее изученными являются: ламинин, коллаген 1-го и 4-го типов, протеогликаны, фибронектин, витронектин. Трехмерное пространственное построе- ние матрикса раскрывает его функцию биологического барьера в проникновении воды, макро- и микромолекул в альвеолярное пространство. Повышенная проницаемость сосудов возникает при повреждении или эндотелиальных клеток, или матрикса. В более тяжелых случаях происходит альтерация как эндотелия, так и матрикса.

В последние годы активно исследуется роль альвеолярных эпителиальных клеток 1-го и 2-го типов в регуляции водного обмена, особенно в тех ситуациях, когда по разным причинам произошла альтерация эндотелиальных клеток капилляров и их матрикса. Альвеолярный эпителий выстилает поверхность альвеол и играет важную роль в движении воды и электролитов. Радиус соединений между эпителиальными клетками не превышает $2 \AA$, что значительно меньше радиуса соединения эндотелиальных клеток капилляров. Большинство липидонерастворимых молекул не могут проникнуть через барьер эпителиальных клеток. Вода и ионы могут проходить в ограниченном количестве этот барьер, в то время как липидорастворимые молекулы, такие как кислород и диоксид углерода, свободно диффундируют через указанный барьер. Принципиально новая информация получена по изучению роли эпителия дистального отдела дыхательных путей в активном транспорте ионов и воды альвеолярного пространства. В экспериментальных моделях отека легких было показано, как эпителиальные клетки дистального отдела дыхательных путей регулируют движение ионов солей и воды (Matthay and Folkesson) [4]. Основной механизм движения электролитов через эпителиальный покров осуществляется за счет осмотического транспорта воды. Изменение гидростатического и онкотического давления сосудов не оказывает влияния на уровень активного транспорта ионов, осуществляемого эпителиальными клетками. На транспорт электролитов оказывает влияние фармакологические субстанции, ингибирующие транспорт натрия через мембрану эпителиальных клеток. На изолированной культуре эпителиальных клеток дистального отдела была показана их роль в осмотическом транспорте воды. Клиренс электролитов и белков осуществляется не одновременно. При отеке легких процесс реабсорбции начинается с воды и ионов солевых растворов, поэтому концентрация белка возрастает. Клиренс альбумина из дыхательных путей рассматривают как прогностический признак острого повреждения легких. Ware and Matthay [5] показали, что в среднем клиренс альвеолярной жидкости составляет 6 ч. Этими же авторами было показано, что эндогенные и экзогенные катехоламины не оказывают влияния на скорость клиренса альвеолярной жидкости.

Легочные лимфатические сосуды представлены густой сетью. Они выполняют функцию дренажной системы, которая специализировалась на удалении жидкости, электролитов; через систему лимфатических сосудов осуществляется трафик лимфоцитов и других форменных элементов крови. Терминаль- 
ные отделы лимфатической системы можно обнаружить в ткани, окружающей легочные сосуды, а также в утолщенной части межальвеолярных перегородок. Различают 2 первичных интерстициальных компартмента: 1 - экстраальвеолярные и альвеолярные и 2 лимфатические сосуды, которые замыкаются в экстраальвеолярном интерстиции. Жидкость, которая оказалась за пределами сосудистой стенки, скапливается в пространстве, окружающей сосуды, откуда она поступает в дистальные концевые отделы лимфатических сосудов. Жидкость поступает в лимфатические сосуды из интерстиция за счет градиента концентрации растворимых соединений. Легочный ток лимфы возрастает с увеличением жидкости в интерстициальной ткани, т. е. с увеличением гидростатического давления в межклеточном пространстве (модифицированный закон Старлинга). Однако следует подчеркнуть, что отсутствует линейная связь между током лимфы и уровнем давления в интерстициальной ткани. При развитии отека легких недостаточность дренажной функции лимфатической системы играет патогенетическую роль в том, что не удается компенсировать гидростатическое давление интерстициальной ткани.

Композиция интерстициальной ткани хорошо охарактеризована. Коллаген 1-го типа представлен густой сетью фибрилл, которые сопровождают и окружают бронхи и идущие параллельно с ними сосуды, входят в состав паренхимы легочной ткани. Нити коллагена выполняют поддерживающую функцию таких морфологических единиц легких, какими является ацинус, межальвеолярные перегородки. Эластические волокна - 2-е по частоте фибриллы легочной ткани. Если фибриллы коллагена выполняют преимущественно функцию морфологической структуры, способной к растяжению, то эластическая ткань играет важную роль в том, чтобы легкие после растяжения вновь восстанавливались в прежних размерах. Эластические волокна преимущественно находятся в терминальных бронхах, альвеолах, в стенках сосудов (эластический тип), они входят в состав плевры. Протеогликаны являются основной субстанцией интерстициальной ткани; они состоят на $20 \%$ из белка и на 80 \% из гликозаминогликанов, молекулярный вес колеблется от 1000 до 4000 кДа. Протеогликаны включают в свой состав сульфат хондроитина, сульфат гепарана и целый ряд других соединений. Матрикс интерстициальной ткани по своей функции напоминает губку, т. е. количество воды может существенно варьироваться в зависимости от гемодинамических изменений. Эти свойства интерстициальной ткани проявляются и в характеристике ее комплайнса: выделяют низкий и высокий уровни комплайнса. Повышение комплайнса происходит при повышении гидростатического давления интерстициальной ткани, что можно рассматривать как определенный механизм защиты альвеолярного пространства от возможного накопления воды на его поверхности.
Существует несколько гипотез, в которых излагаются возможные механизмы повышения проницаемости эндотелиальных клеток. Теория пор относится к числу тех, в которых рассматриваются механизмы проницаемости эндотелиальных клеток альвеолярных капилляров. Поры составляют 0,02 \% от общей поверхности эндотелиальных клеток капилляров альвеол. Теория пор основана на предпосылке, что их радиус позволяет проходить белковым молекулам с определенными размерами. В первую очередь это касается альбумина, молекулярный вес которого меньше по сравнению с другими белками плазмы крови. Поры имеют разные размеры; они колеблются от 50 до $200 \AA$ А. Критический анализ данной теории основан на том, что не учитывается электрический заряд самих эндотелиальных клеток и тех субстанций, которые фильтруются через поры.

Большое внимание в исследованиях было уделено механизмам транспорта альбумина через эндотелиальные клетки альвеолярных капилляров. Альбумин активно транспортируется через эндотелиальные клетки. Основной механизм, через который осуществляется транспорт альбумина, связан со специфическими рецепторами, находящимися на поверхности эндотелиальных клеток. Альбумин связывается с рецептором и посредством трансцитозного механизма в растворенном виде транспортируется через эндотелиальные клетки. При связывании альбумина с рецептором происходит активация тирозинкиназы, что и активирует образование везикул и дальнейший его транспорт через клетку. Клиренс альбумина, который определяется в просвете дыхательных путей при отеке легких, имеет прогностическое значение в оценке тяжести и исходов данного синдрома.

В сосудистой проницаемости принимают участие многие механизмы. Большое внимание уделяется роли биологических агонистов, цитокинов, факторам роста и механическим силам, влияющим на комплайнс легочной ткани. Тромбин, который относиться к сериновым протеиназам, вызывает целый ряд эффектов клеточного ответа. Этот патологический процесс имеет большое значение в исследовании природы острого повреждения легких, который приводит к развитию респираторного дистресс-синдрома. Так, показано, что тромбин увеличивает проницаемость для макромолекул. Приводит к активизации фосфолипазы $\mathrm{A}_{2}, \mathrm{C}, \mathrm{D}$, фактора Виллебранда, эндотелина, оксида азота, увеличивает концентрацию Са в цитозоле. Проницаемость сосуда для плазмы быстро возрастает. В экспериментальных условиях показано, что эффект тромбина реализуется уже к концу 5-й мин. Необходимо подчеркнуть морфологические изменения, которые наступают при остром повреждении легких и последующем развитии отека легких. Они касаются в первую очередь возникновения мест разрыва эндотелиальных клеток. Эти изменения свидетельствуют о глубоких конфирмационных изменениях эндотелиального покрова альвеолярных капилляров. Появление этих морфо- 
логических изменений рассматривают как кардинальный признак воспалительного процесса, приводящего к развитию шокового легкого.

Организация базальной мембраны и экстрацеллюлярного матрикса, окружающих эндотелиальные клетки альвеолярных капилляров, играет важную роль в регуляции движения электролитов, а также альбумина. Транспорт альбумина снижается прежде всего потому, что глюкозаминогликан имеет отрицательный заряд. В исследованиях in vivo было показано, что интерстициальный матрикс в 14 раз снижает диффузионный транспорт альбумина (Fox and Wayland). В проницаемости базальной мембраны большую роль играют интегрины, с которыми связывают локальные эффекты адгезии различных молекул. Этот процесс может привести к нарушению барьерной функции базальной мембраны, что, в частности, наблюдается при остром повреждении легких.

Несмотря на достигнутый прогресс в изучении молекулярных и клеточных механизмов, с нарушением которых связывают повышение сосудистой проницаемости и развитие отека легких, процесс восстановления барьерной функции эндотелиальных клеток альвеолярных капилляров остается областью малоизученной. Механический стресс легочной ткани, вызванный в экспериментальных условиях, приводит к повышению сосудистой проницаемости. Нарушение проницаемости легочного сосудистого барьера происходило при растяжении силой от 1 до 10 дин / см². Компенсаторная реакция проявлялась в увеличении внутриклеточной концентрации циклического АМР, который способен ингибировать эффекты тромбина и гистамина. С повышением концентрации циклического АМР в эндотелиальных клетках альвеолярных капилляров происходило повышение ее барьерной функции, и степень выраженности отека снижалась. Недавно были получены данные по участию сосудистого фактора роста, фактора роста гепатоцитов, ангиопоэтина, сфингозина1-фосфата, которые способны влиять на повышение барьерной функции сосудов. Высокая активность в повышении барьерной функции эндотелиальных клеток была продемонстрирована с применением сфингозин-1-фосфата. Его синтез связывают с экспрессией семейства генов (Edg), контролирующих процесс дифференциации эндотелиальных клеток. Сфингозин-1-фосфат влияет на процесс регенерации межклеточных контактов. Так, под его влиянием происходит редукция межклеточных разрывов. В условиях экспериментальной модели отека легких было продемонстрировано, что одноразовое в/в введение сфингозин-1-фосфата значительно снижает активность многих маркеров острого повреждения легочной ткани; при его назначении происходит быстрая редукция отека легких.

Малоизученной проблемой в механизмах развития острого повреждения легких, отека легких, острого респираторного дистресс-синдрома оставалась роль системы сурфактанта. Частично этот вопрос был решен в исследованиях последних лет, анализ которых был проведен Lewis and Veldhuizen [6]. Сурфактант играет важную роль в транспорте воды и электролитов в альвеолярное пространство и может рассматриваться как один из естественных биологических барьеров. Он подвергается деградации при развившемся отеке легких. Наконец, сурфактант может быть использован как лекарственное средство при ведении больных с респираторным дистресс-синдромом.

Сурфактант состоит из фосфолипидов и протеинов. Фосфатидилхолин является основной составляющей частью сурфактанта; на его долю приходится $>70 \%$ от всех субстанций, входящих в состав сурфактанта, и он более активен в формировании биологической пленки. Сурфактант тонкой пленкой выстилает поверхность альвеол. Его биофизические свойства обеспечивают эффект растяжения альвеол. В таком функциональном состоянии альвеол осуществляется диффузия газов. В современной классификации выделяют 4 вида сурфактанта: A, B, C, D. Гидрофильные свойства определены у SP-A и SP-D, у 2 других - гидрофобные. Синтез сурфактанта осуществляется альвеоцитами 2-го типа; продукты распада утилизируются альвеолярными макрофагами. Морфологическая структура напоминает трубчатый миелин, и лишь небольшое количество сурфактанта представлено в виде агрегатов. Однако количество агрегированных форм возрастает при дегенерации сурфактанта, что наблюдается при остром повреждении легочной ткани. Одной из функций сурфактанта, является его участие в формировании трансмурального гидростатического давления и регуляции количества жидкости, выходящей за пределы сосудистой стенки. Силы натяжения сурфактанта составляют приблизительно $70 \mathrm{mH} / \mathrm{M}^{2}$, при выдохе - снижение до $25 \mathrm{mH} / \mathrm{M}^{2}$. Физиологическая роль сурфактанта обеспечить интерфейс между воздушной средой и эритроцитами для обеспечения диффузии кислорода и диоксида углерода. В случаях острого повреждения легких сурфактант агрегирует, что и приводит к спаданию альвеол. Однако перед этой фазой наблюдается значительное пропитывание жидкости в просвет альвеол - альвеолярная фаза отека легких.

Сурфактант использован в качестве лекарственного средства и нашел свое применение в первую очередь для лечения больных с острым респираторным дистресс-синдромом. Следует подчеркнуть, что сурфактант также может рассматриваться как иммуномодулирующее вещество, поэтому с ним связывают усиление фагоцитарной активности альвеолярных макрофагов. Другим важным его свойством является снижение повреждающей активности оксидантов, что нашло свое применение при необходимости вентилировать больных 100\%-ным кислородом. В настоящее время сурфактант представлен несколькими лекарственными формами. Он назначается системно и инстиллируется в дыхательные пути. Таким образом, сурфактант играет важную роль в формировании барьерной функции альвеол. 
Он влияет на транспорт воды и электролитов и выход их в просвет альвеол. Сурфактант играет патогенетическую роль в механизмах отека легких; его деградация происходит при остром повреждении легких; он может рассматриваться в качестве лекарственного средства при лечении больных с острым респираторным дистресс-синдромом.

Национальный институт здоровья США индуцировал научные исследования по острому повреждению легких; эти исследования включены в программу Генома человека. Центром исследования стал Johns Hopkins University, общим координатором профессор Garcia. Научные проекты и результаты исследований публикуются на сайте www.hopkins-genomics.org [7]. Основным мотивом к проведению этого научного проекта явились в целом неблагоприятные результаты клинических исходов при синдроме острого повреждения легких, смертность при котором превышает $60 \%$. Существует большой разрыв между современными техническими возможностями респираторной поддержки и исходами заболевания. С другой стороны, появились данные о том, что генетическая предрасположенность может влиять на тяжесть клинических проявлений и ответ на проводимые методы лечения. Предварительные данные являются достаточно обнадеживающими. Так, было показано, что гены, кодирующие семейство сурфактанта, ассоциированы с синдромом острого повреждения легких, позволяют выделить фенотипы, имеющие прогностическое значение. Полиморфизм гена, с экспрессией которого связывают синтез SP-B, произошел в положении Th131lle аминокислоты; с ним ассоциируют неблагоприятный прогноз при шоковом легком. Кандидаты гены, по которым в настоящее время проводятся исследования, охватывают коагуляцию, воспаление и иммунитет, хемотаксис, новые гены и др. Среди генов, с экспрессией которых связывают коагулопатии, исследованы следующие: тромбопластин - F3, плазминоген - PAI-1, фибриноген- $\alpha$ - FGA и некоторые др. Гены воспалительного процесса: интерлейкин-1 - IL-1b, интерлейкин-6 - IL-6 и др. Среди новых генов большое внимание привлекает экспрессия эндотелиального дифференцирующего протеина - сфинголипида PBEF. Более подробная информация о генах кандидатах при синдроме острого повреждения легких можно найти на сайте www.hopkins-genomics.org [7].

С позиции клинической практики важно знать основные этапы патофизиологического процесса в формировании отека легких. Это позволяет улучшать качество диагностического процесса, выбирать рациональные методы диагностики, которые в то же самое время обладают высокой степенью чувствительности и специфичности. Особое значение приобретает разработка лечебных программ ведения больных с различными клиническими формами отека легких.

С патофизиологических позиций отек легких может быть рассмотрен как процесс повышенной фильтрации воды, электролитов и белков из микро- сосудистого русла малого круга кровообращения в интерстициальную ткань и альвеолярную поверхность. Процесс реабсорбции аккумулированной жидкости по разным причинам нарушен. Выделяют определенную последовательность в развитии отека легких. На первых этапах в патологический процесс развития отека легких вовлекается область корней легких, в последующем интерстициальная ткань и, наконец, вода, электролиты и белки заполняют поверхность альвеол. Градиент давления при легочном кровообращении имеет вертикальную зависимость. В этом плане малый круг кровообращения отличается от других органов и систем человеческого организма. Так, показатели гидростатического давления сосудов и интерстициальной ткани, давление в плевральной полости и легочные объемы в разных участках легких имеют разные показатели. Распределение воды в легочной ткани также дифференцировано в зависимости от особенностей региональной гемодинамики и вентиляции. Градиент давления в альвеолярно-септальной области микрососудов адвентиции больше всего в апикальной части легких, поэтому аккумуляция воды в этой части легких наибольшая. Это имеет клиническое значение: так, влажные хрипы, которые появляются при развитии отека легких, изначально появляются в верхних отделах легких. Появление влажных хрипов в этой части легких свидетельствует о том, что интерстициальная фаза отека легких перешла в альвеолярную, что прогностически более неблагоприятно. Жидкость, которая аккумулировалась в интерстициальной ткани, не может быть удалена лимфатическими сосудами, которые выполняют дренажную функцию. Мелкого диаметра лимфатические сосуды окружают микрососудистую систему легких и бронхиол. Если лимфатические сосуды не способны обеспечить транспорт жидкости из интерстициальной ткани, то вокруг сосудов появляется феномен "манжетки". В начальных стадиях накопление жидкости легочной тканью приводит к картине очаговых изменений, что проявляется при проведении рентгенологических методов исследования легких. При аккумуляции жидкости в интерстициальной ткани с 35 до 50 \% жидкость начинает проникать на поверхность альвеол, формируется альвеолярный отек легких. На этой стадии происходят значительные нарушения в диффузии кислорода и диоксида углерода, что сказывается на усилении одышки и падении сатурации кислорода $<90 \%$. Точного механизма перехода интерстициальной фазы отека легких в альвеолярную неизвестно. Однако большое значение придается трансэпителиальным механизмам. Открываются поры для прохождения воды и электролитов, нарушается функция каналов: ингибиция калиевых каналов и вхождение кальция в цитозоль гладких мышц сосудистой стенки. Проявлением острого повреждения легких являются межэпителиальные разрывы, что свидетельствует о грубых нарушениях в барьерной функции эпителиальных клеток. 
Универсальным механизмом в развитии отека легких является повышение гидростатического давления в капиллярах альвеол (закон Старлинга). Установлена определенная гемодинамическая зависимость. Повышение давления в левом предсердии (которое можно экстраполировать на давление заклинивания) > 20-25 мм рт. ст. рассматривают как критическое: вероятность развития отека легких высока. Механизмами защиты, противостоящими развитию отека легких, являются: дренажная функция лимфатической системы, резорбция воды в сосуды, дренаж в медиастинальные сосуды, дренаж в плевральную полость, повышение барьерной функции альвеолярного эпителия, снижение сил натяжения сурфактанта, повышение активного транспорта воды и электролитов из дистального отдела дыхательных путей. Все перечисленные механизмы могут противодействовать выходу воды из циркулирующей крови в случаях повышения давления в левом предсердии.

Снижение онкотического давления является также одним из патогенетических механизмов развития отека легких. Снижение концентрации протеинов в плазме, что наблюдается при гипоальбуминемии, сопровождается редукцией абсорбционного онкотического давления в интерстициальной ткани. Этот механизм приводит к увеличению транскапиллярной фильтрации жидкости, таким образом формируется отечный синдром.

Появление в отечной жидкости, которая собирается при отеке легких на поверхности альвеол, макромолекул, лейкоцитов свидетельствует о глубоких патологических изменениях в проницаемости эпителиальных и эндотелиальных клеток. Морфологическим маркером этих глубоких изменений является появление разрывов в клеточных соединениях. Комплекс медиаторов воспаления, активных форм кислорода, повышение протеолитической активности приводят к этим морфологическим процессам. Подобного рода изменения сопровождаются развитием остро протекающего отека легких. Лимфатические сосуды способны удалить значительное количество жидкости из интерстициального пространства, плевральной полости. Пропульсационная деятельность лимфатических сосудов определяется инспираторным и экспираторным актами респираторного цикла, а также функциональной активностью клапанов сосудов. Необходимо подчеркнуть, что линейной зависимости между током лимфы и гидростатическим давлением в интерстициальной ткани не существует. Однако следует констатировать, что недостаточность лимфатической системы является одним из ведущих патогенетических факторов в переходе от интерстициальной фазы отека легких в альвеолярную.

Таким образом, легочное кровообращение предназначено обеспечить как респираторную, так и нереспираторную функцию легких. Эволюционно эта система предназначена обеспечить диффузию кислорода в циркулирующие эритроциты и элиминировать диоксид углерода из организма человека. Низкое давление, низкое сопротивление сосудов являются уникальными свойствами легочного кровообращения, и этим оно существенно отличается от системного кровообращения. Гравитационный эффект в распределении крови более характерен для легочной ткани, чем это можно констатировать в отношении других органов и систем человеческого организма. Другой уникальной особенностью легочного кровообращения является реакция прекапилляров на гипоксию, которая проявляется вазоспастическим эффектом, в то время как в системном кровообращении гипоксия приводит к вазодилатационному эффекту.

При развитии отека легких легочные микрососуды являются первичным местом, где вода и электролиты выходят за сосудистую стенку. Фильтрация жидкости относится к физиологическим процессам, но в случае развития отека легких баланс жидкости, поступившей в экстрасосудистое пространство, превышает способность легких ее элиминировать. Происходят патологические изменения, в которых участвуют медиаторы воспалительной реакции, активные формы кислорода, ферменты с протеолитической активностью, которые и оказывают влияние на формирование гидростатического давления и изменения сосудистой проницаемости. В последние годы внимание уделяется исследованию межклеточных взаимодействий и их нарушений при развитии острого повреждения легких. Эти патологические процессы затрагивают также трансэпителиальный и трансэндотелиальный транспорт, функциональное состояние базальной мембраны. В конечной фазе развития отека легких происходит абнормальное накопление белков, в первую очередь альбуминов, в альвеолярной жидкости.

\section{Литература}

1. Albertine K., Williams V., Hyde D.: Anatomy of the lungs, part 1. Jn: Mason R., Broaddus C., Murray J., Nadel J. Textbook of respiratory medicine. New York: Elsevier Saunder; 2005; vol. 1: 2-29.

2. Fishman A. The pulmonary circulation normal and abnormal. Philadelphia; 1990.

3. Mason R., Broaddus C., Murray J., Nadel J.: Textbook of respiratory medicine. New York: Elsevier Saunders; 2005; vol. 1-2.

4. Matthay M., Folkesson H.: Alveolar and distal airway epithelial fluid transport. Jn: Mason R., Broaddus C., Murray J., Nadel J. Textbook of respiratory medicine. New York: Elsevier Saunder; 2005; vol. 1: 322-328.

5. Ware L., Matthay M.: Alveolar fluid clearance is impaired in the majority of patients with acute lung injury and acute respiratory distress syndrome. Am. J. Respir. Crit. Care Med. 2001; 163: 1376-1383.

6. Lewis J., Veldhuizen R.: The role of exogenous surfactant in the treatment of acute lung injury. Annu. Rev. Physiol, 2003, 65: $1-31$.

7. http:www.hopkins-genomics.org

8. Matthay M., Martin T.: Pulmonary edema and acute lung injury. Jn: Mason R., Broaddus C., Murray J., Nadel J. Textbook of respiratory medicine. New York: Elsevier Saunder; 2005; vol. 2: 1502-1571. 